\title{
The Impact of Segmentectomy Versus Lobectomy on Pulmonary Function in Patients With Non-small-cell Lung Cancer: a Meta-analysis
}

\author{
Yuan Xu \\ Peking Union Medical College Hospital \\ Yingzhi Qin \\ Peking Union Medical College Hospital \\ Dongjie Ma \\ Peking Union Medical College Hospital \\ Hongsheng Liu ( $\nabla$ hongshengliu16@163.com) \\ Peking Union Medical College Hospital
}

\section{Research article}

Keywords: non-small-cell lung cancer, segmentectomy, lobectomy, pulmonary function

Posted Date: November 16th, 2021

DOI: https://doi.org/10.21203/rs.3.rs-1048811/v1

License: (c) This work is licensed under a Creative Commons Attribution 4.0 International License. Read Full License 


\section{Abstract}

Objective: Segmentectomy has been reported as an alternative to lobectomy for small-sized NSCLC without detriment to survival. The long-term benefits of segmentectomy over lobectomy on pulmonary function have not been firmly established. This meta-analysis aims to compare postoperative changes in pulmonary function in NSCLC patients undergoing segmentectomy or lobectomy.

Methods: Medline, Embase, Web of Science and Scopus were searched through March 2021. Statistical comparisons were made when appropriate.

Results: Fourteen studies (2412 participants) out of 324 citations were included in this study. All selected studies were high quality, as indicated by the Newcastle-Ottawa scale for assessing the risk of bias. Clinical outcomes were compared between segmentectomy and lobectomy. $\triangle F E V 1$ [10 studies, $\mathrm{P}<0.01, \mathrm{WMD}=0.40(0.29,0.51)], \Delta \mathrm{FVC}[4$ studies, $\mathrm{P}<0.01, \mathrm{WMD}=0.16(0.07,0.24)], \Delta \mathrm{FVC} \%[4$ studies, $\mathrm{P}<0.01, \mathrm{WMD}=4.05(2.32,5.79)]$, $\triangle$ FEV1/FVC [2 studies, $P<0.01, \mathrm{WMD}=1.99(0.90,3.08)]$, and $\triangle \mathrm{DLCO}[3$ studies, $\mathrm{P}<0.01, \mathrm{WMD}=1.30(0.69,1.90)]$ were significantly lower in the segmentectomy group than in the lobectomy group. Subgroup analysis showed that in stage IA patients, the $\Delta F E V 1 \%[3$ studies, $\mathrm{P}<0.01$, WMD $=$ $0.26(0.07,0.46)]$ was significantly lower in the segmentectomy group. The $\triangle \mathrm{DLCO} \%$ and $\triangle \mathrm{MVV} \%$ were incomparable.

Conclusion: Segmentectomy preserves more lung function than lobectomy. There were significantly smaller decreases in FEV1, FVC, FVC\%, FEV1/FVC and DLCO in the segmentectomy group than in the lobectomy group.

\section{Introduction}

Lung cancer is one of the leading cause of cancer-related death worldwide (1). Surgical resection for non-small-cell lung cancer (NSCLC) is the standard treatment that leads to the best chance of a cure. For the 100-year history of surgery, lobectomy has remained the gold standard for operable NSCLC. In recent years, segmentectomy has been reported as an alternative to lobectomy for small-sized NSCLC without detriment in survival (2). Theoretically, segmentectomy has an advantage over lobectomy on anatomical functional. However, the long-term benefits of segmentectomy over lobectomy on pulmonary function have not been firmly established. Reports related to the utility of segmentectomy in preserving lung function are conflicting. The purpose of this study was to perform a meta-analysis to compare postoperative changes in pulmonary function in NSCLC patients undergoing segmentectomy or lobectomy.

\section{Methods}

\section{Inclusion and Exclusion Criteria}

Studies were included if they met the following inclusion criteria: (1) patients diagnosed with NSCLC underwent surgical treatment; (2) comparative data between segmentectomy and lobectomy were available; and (3) preoperative and postoperative pulmonary function data were available. The outcomes included forced expiratory volume in 1 second (FEV1), predicted FEV1 percentage (FEV1\%), forced vital capacity (FVC), predicted FVC percentage (FVC\%), FEV1/FVC, maximal voluntary ventilation (MVV), diffusion capacity of carbon monoxide (DLCO) and predicted DLCO percentage (DLCO\%). Studies were excluded if the full text was not in English or could not be accessed.

\section{Search Strategy}

Medline, Embase, Web of Science and Scopus were searched through May 2021. The following search terms and strategies were used: (1) respiratory function OR pulmonary function OR FEV1 OR FVC OR MVV OR DLCO; (2) lung cancer; (3) lobectomy AND (segmentectomy OR sublobar resection OR limited resection), and (1) AND (2) AND (3). Data were extracted with a standardized form. The Newcastle-Ottawa Scale (NOS) was used for quality assessment.

\section{Statistical Analysis}

Inconsistency between studies was quantified by calculating the $\mathrm{I}^{2}$ statistic. Continuous variables were reported as weighted mean differences (WMDs) and $95 \%$ confidence intervals (95\% Cls). A random-effects model was used for heterogeneous data $\left(I^{2}>50 \%\right)$, whereas a fixed-effects model was used for homogenous data $\left(I^{2}<50 \%\right)$. P $<0.05$ was considered to be statistically significant. SAS software, version 9.1 (SAS Institute, Cary, NC, USA) and Review Manager, version 5.4 (The Cochrane Collaboration) were used to perform statistical analysis.

\section{Results}

\section{Search Results}

The initial database search identified 172 articles in Medline, 251 in Embase, 154 in Web of Science and 166 in Scopus. After excluding duplicate records, 324 studies were included. A total of 273 articles were excluded because they failed to meet the inclusion criteria after review of the abstracts and titles. An additional 37 articles were excluded after the full text review. Hence, a total of 14 studies (13 retrospective and 1 prospective

Page 2/9 
observational) including 2412 patients (976 sublobar resection and 1436 lobectomy) were finally selected. The detailed selection process is shown in Figure 1.

The major characteristics of the participants in the included studies are shown in Table 1. Patients in 8 studies had NSCLC with TNM stage I. Six studies included the VATS approach only, 2 included the open approach only, and 3 included both. Two studies included wedge resections. The follow-up time (from surgery to postoperative pulmonary function) ranged from 3 to 60 months.

Table 1

Basic characteristics of the included studies.

\begin{tabular}{|c|c|c|c|c|c|c|c|c|c|c|c|}
\hline \multirow[t]{2}{*}{ ID } & \multirow[t]{2}{*}{ Location } & \multirow{2}{*}{$\begin{array}{l}\text { Enrolment } \\
\text { Year }\end{array}$} & \multirow{2}{*}{$\begin{array}{l}\text { Total } \\
\text { No. }\end{array}$} & \multirow{2}{*}{$\begin{array}{l}\text { No. of } \\
\text { segmentectomy }\end{array}$} & \multirow{2}{*}{$\begin{array}{l}\text { TNM } \\
\text { stage }\end{array}$} & \multirow[t]{2}{*}{ Approach } & \multirow{2}{*}{$\begin{array}{l}\text { Wedge } \\
\text { resection } \\
\text { included }\end{array}$} & \multicolumn{3}{|c|}{ Involved lobe } & \multirow{2}{*}{$\begin{array}{l}\text { Follow- } \\
\text { up } \\
\text { (month) }\end{array}$} \\
\hline & & & & & & & & Upper & Middle & Lower & \\
\hline $\begin{array}{l}\text { Kim } \\
(22)\end{array}$ & Korea & $\begin{array}{l}2003- \\
2012\end{array}$ & 300 & 73 & I-IV & VATS & yes & NM & & & $3 \& 12$ \\
\hline \multirow{2}{*}{$\begin{array}{l}\text { Zhong } 2020 \\
\text { (24) }\end{array}$} & \multirow[t]{2}{*}{ China } & \multirow{2}{*}{$\begin{array}{l}2014- \\
2016\end{array}$} & \multirow[t]{2}{*}{144} & \multirow[t]{2}{*}{68} & \multirow[t]{2}{*}{ IA-IB } & \multirow[t]{2}{*}{ VATS } & \multirow[t]{2}{*}{ no } & 35 & 9 & 24 & \multirow[t]{2}{*}{6} \\
\hline & & & & & & & & 37 & 11 & 28 & \\
\hline \multirow{2}{*}{$\begin{array}{l}\text { Nomori } \\
2018 c\end{array}$} & \multirow[t]{2}{*}{ Japan } & \multirow{2}{*}{$\begin{array}{l}2013- \\
2016\end{array}$} & \multirow[t]{2}{*}{206} & \multirow[t]{2}{*}{103} & \multirow[t]{2}{*}{ NM } & \multirow[t]{2}{*}{ VATS+open } & \multirow[t]{2}{*}{ no } & 57 & 0 & 46 & \multirow[t]{2}{*}{6} \\
\hline & & & & & & & & 57 & 0 & 46 & \\
\hline \multirow{2}{*}{$\begin{array}{l}\text { Takizawa } \\
1999 \text { (25) }\end{array}$} & \multirow[t]{2}{*}{ Japan } & 1993- & 80 & 40 & IA & open & no & 25 & 0 & 15 & 12 \\
\hline & & & & & & & & 28 & 0 & 12 & \\
\hline Tane 2019 & Japan & $2012-$ & 148 & 74 & IA1- & VATS & no & 45 & 0 & 29 & 6 \\
\hline & & & & & & & & 45 & 0 & 29 & \\
\hline $\begin{array}{l}\text { Helminen } \\
2020 \text { (1) }\end{array}$ & Japan & $\begin{array}{l}2007- \\
2019\end{array}$ & 215 & 105 & $|-| I \mid$ & VATS & no & NM & & & NM \\
\hline Gu 2018 (26) & China & 2011- & 109 & 34 & IA & VATS & yes & 23 & 0 & 11 & 6 \\
\hline & & & & & & & & 50 & 0 & 25 & \\
\hline $\begin{array}{l}\text { Kobayashi } \\
2017(18)\end{array}$ & Japan & $\begin{array}{l}2001- \\
2009\end{array}$ & 346 & 118 & $|-| I \mid$ & VATS+open & no & NM & & & $12 \& 60$ \\
\hline Keenan 2004 & USA & 1996- & 201 & 54 & IA & NM & no & 23 & 0 & 31 & 12 \\
\hline & & & & & & & & 87 & 17 & 43 & \\
\hline Kashiwabara & Japan & $2000-$ & 118 & 71 & I & NM & no & 38 & 0 & 33 & 6 \\
\hline & & & & & & & & 32 & 0 & 15 & \\
\hline Macke 2015 & USA & 1996- & 159 & 77 & I & VATS+open & no & 36 & 9 & 32 & $6-36$ \\
\hline & & & & & & & & 48 & 0 & 34 & \\
\hline Saito 2014 & Japan & 2006- & 178 & 52 & I & open & no & 30 & 0 & 22 & 6 \\
\hline & & & & & & & & 71 & 6 & 49 & \\
\hline Yoshimoto & Japan & 2005- & 20 & 13 & NM & NM & no & 13 & 0 & 0 & 5 \\
\hline & & & & & & & & 7 & 0 & 0 & \\
\hline $\begin{array}{l}\text { Hwang } 2015 \\
(21)\end{array}$ & Korea & $\begin{array}{l}2005- \\
2013\end{array}$ & 188 & 94 & I-IV & VATS & no & NM & & & NM \\
\hline
\end{tabular}

\section{Quality Assessment}

The quality of the included studies was assessed using the NOS (www.ohri.ca/programs/clinical_epidemiology/oxford.htm). Two independent reviewers conducted the assessment. Disagreements were resolved by discussion. Of the studies, seven scored 9 points, four scored 8 points, two scored 7 points, and one scored 6 points, indicating that all the studies had relatively high quality (Table 2). 
Table 2

Quality assessment according to the Newcastle-Ottawa scale.

\begin{tabular}{|lllll|}
\hline ID & Selection & Comparability & Exposure & Total score \\
\hline Kim 2015 (22) & 3 & 2 & 3 & 8 \\
\hline Zhong 2020 (24) & 4 & 2 & 2 & 8 \\
\hline Nomori 2018 (7) & 4 & 2 & 3 & 9 \\
\hline Takizawa 1999 (25) & 4 & 2 & 3 & 9 \\
\hline Tane 2019 (3) & 4 & 2 & 3 & 9 \\
\hline Helminen 2020 (1) & 3 & 2 & 2 & 7 \\
\hline Gu 2018 (26) & 4 & 2 & 3 & 9 \\
\hline Kobayashi 2017 (18) & 4 & 2 & 3 & 9 \\
\hline Keenan 2004 (4) & 2 & 1 & 3 & 6 \\
\hline Kashiwabara 2009 (16) & 4 & 2 & 3 & 9 \\
\hline Macke 2015 (14) & 4 & 2 & 3 & 9 \\
\hline Saito 2014 (27) & 4 & 1 & 3 & 8 \\
\hline Yoshimoto 2010 (28) & 3 & 2 & 2 & 7 \\
\hline Hwang 2015 (21) & 4 & 2 & 2 & 8 \\
\hline
\end{tabular}

\section{Clinical Outcomes FEV1 \& FEV1\%}

FEV1 was the most frequently reported functional value. It was recorded in 10 studies $\left(n=1664, I^{2}=95 \%\right.$, random-effects model, Figure S1). The mean $\triangle \mathrm{FEV} 1$ varied from -0.10 to -0.44 (segmentectomy group) and -0.23 to -0.50 (lobectomy group). After ruling out one study with high heterogeneity (3), the $\triangle F E V 1$ was significantly lower in the segmentectomy group than in the lobectomy group $[P<0.01, W M D=0.40(0.29,0.51)$; heterogeneity: $\mathrm{Chi}^{2}=7.45, \mathrm{df}=8, \mathrm{P}=0.49 ; \mathrm{I}^{2}=0 \%$, fixed-effects model; Figure 2].

The FEV1\% was incomparable due to the high heterogeneity (8 studies, $\mathrm{n}=1633, \mathrm{I}^{2}=96 \%$, random-effects model, Figure S2). The mean $\Delta \mathrm{FEV} 1 \%$ varied from $-9.2 \%$ to $+1.0 \%$ (segmentectomy group) and $-16.2 \%$ to $-8.1 \%$ (lobectomy group). Subgroup analysis showed that in stage IA patients, the $\triangle$ FEV1\% was significantly lower in the segmentectomy group [3 studies, $n=427 ; \mathrm{P}<0.01, \mathrm{WMD}=0.26(0.07,0.46)$; heterogeneity: Chi ${ }^{2}=2.13, \mathrm{df}=2$, $P=0.35 ; I^{2}=6 \%$, fixed-effects model; Figure 3].

\section{FVC \& FVC\%}

Four studies $(\mathrm{n}=607$ ) provided FVC values. The mean $\triangle \mathrm{FVC}$ varied from -0.07 to -0.46 (segmentectomy group) and -0.23 to -0.6 (lobectomy group). The $\triangle F V C$ was significantly lower in the segmentectomy group than in the lobectomy group $[P<0.01, W M D=0.16(0.07,0.24)$; heterogeneity: $\mathrm{Chi}^{2}=0.38, \mathrm{df}=3, \mathrm{P}=0.94 ; \mathrm{I}^{2}=0 \%$, fixed-effects model; Figure 4].

The FVC\% was reported in 4 studies ( $n=725,12=79 \%$, random-effects model, Figure S3). After ruling out one study with high heterogeneity (4), the $\triangle \mathrm{FVC} \%$ was significantly lower in the segmentectomy group than in the lobectomy group $\left[\mathrm{P}<0.01, \mathrm{WMD}=4.05(2.32,5.79)\right.$; heterogeneity: Chi ${ }^{2}=$ $0.70, \mathrm{df}=2, \mathrm{P}=0.71 ; \mathrm{I}^{2}=0 \%$, fixed-effects model; Figure 5$]$. The $\Delta \mathrm{FVC} \%$ varied from $-1.5 \%$ to $-10.5 \%$ in the segmentectomy group and $-4.4 \%$ to $-13.7 \%$ in the lobectomy group.

\section{Other outcomes}

The $\triangle \mathrm{FEV} 1 / \mathrm{FVC}$ was significantly lower in the segmentectomy group than in the lobectomy group [2 studies, $\mathrm{n}=646 ; \mathrm{P}<0.01, \mathrm{WMD}=1.99(0.90$, 3.08); heterogeneity: $\mathrm{Chi}^{2}=0.48, \mathrm{df}=1, \mathrm{P}=0.49 ; \mathrm{I}^{2}=0 \%$, fixed-effects model; Figure 6]. The $\Delta \mathrm{FEV} 1 / \mathrm{FVC}$ varied from -0.3 to -1.9 in the segmentectomy group and -1.8 to -4.2 in the lobectomy group.

Similarly, the $\triangle \mathrm{DLCO}$ was significantly lower in the segmentectomy group [3 studies, $\mathrm{P}<0.01, \mathrm{WMD}=1.30(0.69,1.90)$; heterogeneity: Chi ${ }^{2}=2.92, \mathrm{df}$ $=2, \mathrm{P}=0.23 ; \mathrm{I}^{2}=31 \%$, fixed-effects model; Figure 7$]$. The $\Delta \mathrm{DLCO}$ varied from -0.07 to -2.6 in the segmentectomy group and -1.8 to -3 in the lobectomy group. 
The $\triangle D L C O \%\left(n=660, I^{2}=96 \%\right.$, random-effects model, Figure S4) and $\Delta M V V \%\left(n=345, I^{2}=96 \%\right.$, random-effects model, Figure S5) were incomparable.

\section{Discussion}

Previous studies suggested that segmentectomy confers little functional advantage over lobectomy (4). It was concluded that lobectomy should remain the procedure of choice despite the slight functional advantage of limited resection. In the present study, we compared postoperative changes in pulmonary function in patients undergoing segmentectomy or lobectomy. This meta-analysis showed that there were significantly fewer decreases in FEV1, FVC, FVC\%, FEV1/FVC and DLCO in the segmentectomy group than in the lobectomy group. Subgroup analysis also showed that the decrease in FEV1\% was significantly less in the segmentectomy group in stage IA patients. Altogether, these studies support the assumption that segmentectomy preserves more lung function than lobectomy.

Pulmonary function tests are recommended in all patients who undergo thoracic surgery (5). Theoretically, segmentectomy has an anatomical functional advantage over lobectomy. First, as the adult lung cannot regenerate new alveolar septal tissues, postoperative pulmonary function is mainly determined by the amount of lung resected. Second, anatomical excursion of the nonoperated lobe after lobectomy occurred. For example, a right upper lobectomy will damage the function of the middle lobe due to the kink of the middle lobar bronchus and pulmonary artery (6). Third, compensatory lung growth could already have occurred in the ipsilateral nonoperated lobe in the lobectomy group before the operation due to the decreased function in the operated lobe, resulting in less space for postoperative lung growth (7).

FEV1 is an indicator of airway resistance. Changes in FEV1 are largely related to ventilation mechanisms, including existing airway obstruction, compensatory expansion of the residual lung, and chest wall activity (8). Lung resection will inevitably lead to displacement of the remaining lobe. The meta-analysis showed that the decrease in FEV1 was higher in the lobectomy group, indicating that lobectomy is more likely to increase airway resistance. Changes in the FVC are mainly determined by the amount of lung tissue resected. After lung resection, the remaining part of the lung expands and compensates for the resected lobe (9). The meta-analysis showed that both FVC and FVC\% were more rapidly improved in the segmentectomy group, indicating that segmentectomy has an advantage in the preservation of lung volume. FEV1/FVC is an essential parameter to phenotype the functional pattern of patients if obstructive, restrictive or normal (10). There were only 2 studies reporting changes in FEV1/FVC. The meta-analysis showed that the $\triangle \mathrm{FEV} 1 / \mathrm{FVC}$ was lower in the segmentectomy group. DLCO reflects the capillary surface area available for gas diffusion. Preoperative DLCO has been demonstrated to predict the risk of complications, short- and long-term outcomes and the length of hospitalization in patients undergoing thoracic surgery (11). The meta-analysis showed a lower degree of DLCO decrease in the segmentectomy group, indicating that it had better preservation of oxygenation.

Pulmonary function after lung resection can be affected by a number of factors. The number of resected segments is an important factor. Several studies observed a positive relationship between the number of resected segments and the loss of pulmonary function (12-14). As each lobe consisted of different numbers of segments, the improvement of pulmonary function was also determined by the resected lobe. Therefore, Macke et al. classified patients into the following two groups: those who had 1-2 segments resected and those who had 3-5 segments resected (14). This classification could reduce the influence of different lobes and could be adopted in future studies. Furthermore, anatomical excursion of the remaining lobe could also influence the preservation rate of the residual lobe. As mentioned above, right upper lobectomy can cause a reduction in the volume of the right middle lobe (15). Tane et al. found that residual lobe function was the most preserved after S6 segmentectomy, suggesting that the shape of the preserved segments (basal segment) may be amenable to inflation without anatomic displacement (3).

Emphysema could also affect postoperative pulmonary function. Kashiwabara et al. reported that there were some patients with emphysema receiving lobectomy who had a greater advantage in postoperative pulmonary functions than segmentectomy (16). It was speculated that the removal of an emphysematous parenchyma may have caused a partial improvement of the regional lung volume distribution and ventilation inhomogeneity, thus causing 'compensatory lung growth'. However, the selected studies rarely described whether they included patients with emphysema or chronic obstructive pulmonary disease (COPD), which might result in increased heterogeneity.

The influence of the surgical approach on pulmonary function is controversial. Some researchers reported that no differences were found between VATS surgery and open surgery $(19,20)$. In contrast, some studies showed low functional loss after VATS segmentectomy, indicating that the functional benefit of segmentectomy may add to that of VATS (21-23). The selected studies in this meta-analysis contained both VATS and open approaches. Subgroup analysis failed due to the high heterogeneity. More data are needed to achieve a convincing conclusion.

The influence of follow-up time on the recovery of pulmonary function was small. Koike et al. showed that postoperative VC and FEV1 gradually increased within 3 months of surgery and remained stable thereafter (17). Similarly, Kobayashi et al. found that the VC\% and FEV1\% remained almost the same 1 year after surgery (18). It was suggested that the decreases in VC and FEV1 are caused by ageing and are not affected by the operation (18).

Our study has several limitations. The lack of prospective studies influences the data quality. In addition, several factors (e.g., smoking status, complications, surgical procedure, pathological type, adjuvant therapy, and patient effort in pulmonary function tests) that may influence pulmonary function were not included in the selected studies, adding to the heterogeneity. Third, only English literature was included in our study. We also 
found several articles written in Japanese, Turkish or Chinese when searching for studies. This meta-analysis may be more broadly representative if we include studies in all languages.

\section{Conclusion}

This meta-analysis suggests that segmentectomy preserves more lung function than lobectomy. There were significantly smaller decreases in FEV1, FVC, FVC\%, FEV1/FVC and DLCO in the segmentectomy group than in the lobectomy group. Therefore, segmentectomy can be regarded as an alternative therapy for NSCLC.

\section{Declarations}

\section{Ethics approval and consent to participate}

This article does not contain any studies with human participants or animals performed by any of the authors.

\section{Consent for publication}

Not applicable.

\section{Availability of data and materials}

The data are available on request.

\section{Competing interests}

The authors declare that they have no competing interests.

\section{Funding}

This study is not supported by any fundings.

\section{Relevant acknowledgments}

We thank all the staff members, statistical analysts, and quality control members who participated in the study.

\section{Author contributions}

Yuan Xu and Yingzhi Qin conducted the literature review and data collection. Dongjie Ma performed the data analysis. Yuan Xu and Hongsheng Liu wrote the manuscript. All authors read and approved the final manuscript.

\section{Disclosure of conflicts of interest}

All the authors confirm that there are no conflicts of interest.

\section{References}

1. Helminen $\mathrm{O}$, Valo J, Andersen H, Lautam $\square$ ki A, R $\square$ s $\square$ nen J, Sihvo E. Thoracoscopic segmentectomy with simple routine bronchoscopic inflation for intersegmental plane identification: short and midterm outcomes compared with lobectomy. J THORAC DIS. 2020;12(6):3073-84.

2. Migliore M, Fornito M, Palazzolo M, Criscione A, Gangemi M, Borrata F, et al. Ground glass opacities management in the lung cancer screening era. Ann Transl Med. 2018 2018-03-01;6(5):90.

3. Tane S, Nishio W, Nishioka Y, Tanaka H, Ogawa H, Kitamura Y, et al. Evaluation of the Residual Lung Function After Thoracoscopic Segmentectomy Compared With Lobectomy. ANN THORAC SURG. 2019 1990-11-01;108(5):1543-50.

4. Keenan RJ, Landreneau RJ, Jr. Maley RH, Singh D, Macherey R, Bartley S, et al. Segmental resection spares pulmonary function in patients with stage I lung cancer. ANN THORAC SURG. 2004 1990-07-01;78(1):228-33, 228-33.

5. BTS guidelines: guidelines on the selection of patients with lung cancer for surgery. THORAX. 2001 2001-02-01;56(2):89-108.

6. Ueda K, Tanaka T, Hayashi M, Li TS, Kaneoka T, Tanaka N, et al. Compensation of pulmonary function after upper lobectomy versus lower lobectomy. J Thorac Cardiovasc Surg. 2011 2011-10-01;142(4):762-7.

7. Nomori H, Shiraishi A, Cong Y, Sugimura H, Mishima S. Differences in postoperative changes in pulmonary functions following segmentectomy compared with lobectomy. Eur J Cardiothorac Surg. 2018 1990-03-01;53(3):640-7.

8. Seok Y, Cho S, Lee JY, Yang HC, Kim K, Jheon S. The effect of postoperative change in bronchial angle on postoperative pulmonary function after upper lobectomy in lung cancer patients. Interact Cardiovasc Thorac Surg. 2014 2014-02-01;18(2):183-8. 
9. Sengul AT, Sahin B, Celenk C, Basoglu A. Postoperative lung volume change depending on the resected lobe. Thorac Cardiovasc Surg. 2013 2013-03-01;61(2):131-7.

10. Santus P, Franceschi E, Radovanovic D. Sublobar resection: functional evaluation and pathophysiological considerations. J THORAC DIS. 2020 2020-06-01;12(6):3363-8.

11. Almquist D, Khanal N, Smith L, Ganti AK. Preoperative Pulmonary Function Tests (PFTs) and Outcomes from Resected Early Stage Non-small Cell Lung Cancer (NSCLC). ANTICANCER RES. 2018 2018-05-01;38(5):2903-7.

12. Nomori H, Shiraishi A, Cong $Y$, Sugimura H, Mishima S. Differences in postoperative changes in pulmonary functions following segmentectomy compared with lobectomy. Eur J Cardiothorac Surg. 2018 2018-03-01;53(3):640-7.

13. Harada H, Okada M, Sakamoto T, Matsuoka H, Tsubota N. Functional advantage after radical segmentectomy versus lobectomy for lung cancer. ANN THORAC SURG. 2005 2005-12-01;80(6):2041-5.

14. Macke RA, Schuchert MJ, Odell DD, Wilson DO, Luketich JD, Landreneau RJ. Parenchymal preserving anatomic resections result in less pulmonary function loss in patients with Stage I non-small cell lung cancer. J CARDIOTHORAC SURG. 2015 1990-04-01;10:49.

15. Yoshimoto K, Nomori H, Mori T, Ohba Y, Shiraishi K, Tashiro K, et al. Postoperative change in pulmonary function of the ipsilateral preserved lung after segmentectomy versus lobectomy. Eur J Cardiothorac Surg. 2010 1990-01-01;37(1):36-9.

16. Kashiwabara K, Sasaki J, Mori T, Nomori H, Fujii K, Kohrogi H. Relationship between functional preservation after segmentectomy and volumereduction effects after lobectomy in stage I non-small cell lung cancer patients with emphysema. J THORAC ONCOL. 2009 1990-0901;4(9):1111-6.

17. Nakata M, Saeki H, Yokoyama N, Kurita A, Takiyama W, Takashima S. Pulmonary function after lobectomy: video-assisted thoracic surgery versus thoracotomy. ANN THORAC SURG. 2000 2000-09-01;70(3):938-41.

18. Giudicelli R, Thomas P, Lonjon T, Ragni J, Morati N, Ottomani R, et al. Video-assisted minithoracotomy versus muscle-sparing thoracotomy for performing lobectomy. ANN THORAC SURG. 1994 1994-09-01;58(3):712-7, 717-8.

19. Hwang Y, Kang CH, Kim HS, Jeon JH, Park IK, Kim YT. Comparison of thoracoscopic segmentectomy and thoracoscopic lobectomy on the patients with non-small cell lung cancer: a propensity score matching study. Eur J Cardiothorac Surg. 2015 2015-08-01;48(2):273-8.

20. Kim SJ, Lee YJ, Park JS, Cho YJ, Cho S, Yoon HI, et al. Changes in pulmonary function in lung cancer patients after video-assisted thoracic surgery. ANN THORAC SURG. 2015 1990-01-01;99(1):210-7.

21. Watanabe A, Ohori S, Nakashima S, Mawatari T, Inoue N, Kurimoto Y, et al. Feasibility of video-assisted thoracoscopic surgery segmentectomy for selected peripheral lung carcinomas. Eur J Cardiothorac Surg. 2009 2009-05-01;35(5):775-80, 780.

22. Zhong N, Mi Y, Huang B, Chen G, Yu G. Comparison of efficacy between thoracoscopic anatomic segmentectomy and thoracoscopic lobectomy in treating early-stage non-small cell lung cancer. Journal of B.U.ON. 2020;25(1):255-61.

23. Takizawa T, Haga M, Yagi N, Terashima M, Uehara H, Yokoyama A, et al. Pulmonary function after segmentectomy for small peripheral carcinoma of the lung. J Thorac Cardiovasc Surg. 1999 1990-09-01;118(3):536-41.

24. Gu Z, Wang H, Mao T, Ji C, Xiang Y, Zhu Y, et al. Pulmonary function changes after different extent of pulmonary resection under video-assisted thoracic surgery. J THORAC DIS. 2018 1990-04-01;10(4):2331-7.

25. Kobayashi N, Kobayashi K, Kikuchi S, Goto Y, Ichimura H, Endo K, et al. Long-term pulmonary function after surgery for lung cancer. Interact Cardiovasc Thorac Surg. 2017 1990-05-01;24(5):727-32.

26. Saito H, Nakagawa T, Ito M, Imai K, Ono T, Minamiya Y. Pulmonary function after lobectomy versus segmentectomy in patients with stage I nonsmall cell lung cancer. WORLD J SURG. 2014 1990-08-01;38(8):2025-31.

27. Yoshimoto K, Nomori H, Mori T, Ohba Y, Shibata H, Tashiro K, et al. A segmentectomy of the right upper lobe has an advantage over a right upper lobectomy regarding the preservation of the functional volume of the right middle lobe: analysis by perfusion single-photon emission computed tomography/computed tomography. SURG TODAY. 2010 2010-07-01;40(7):614-9.

\section{Figures}




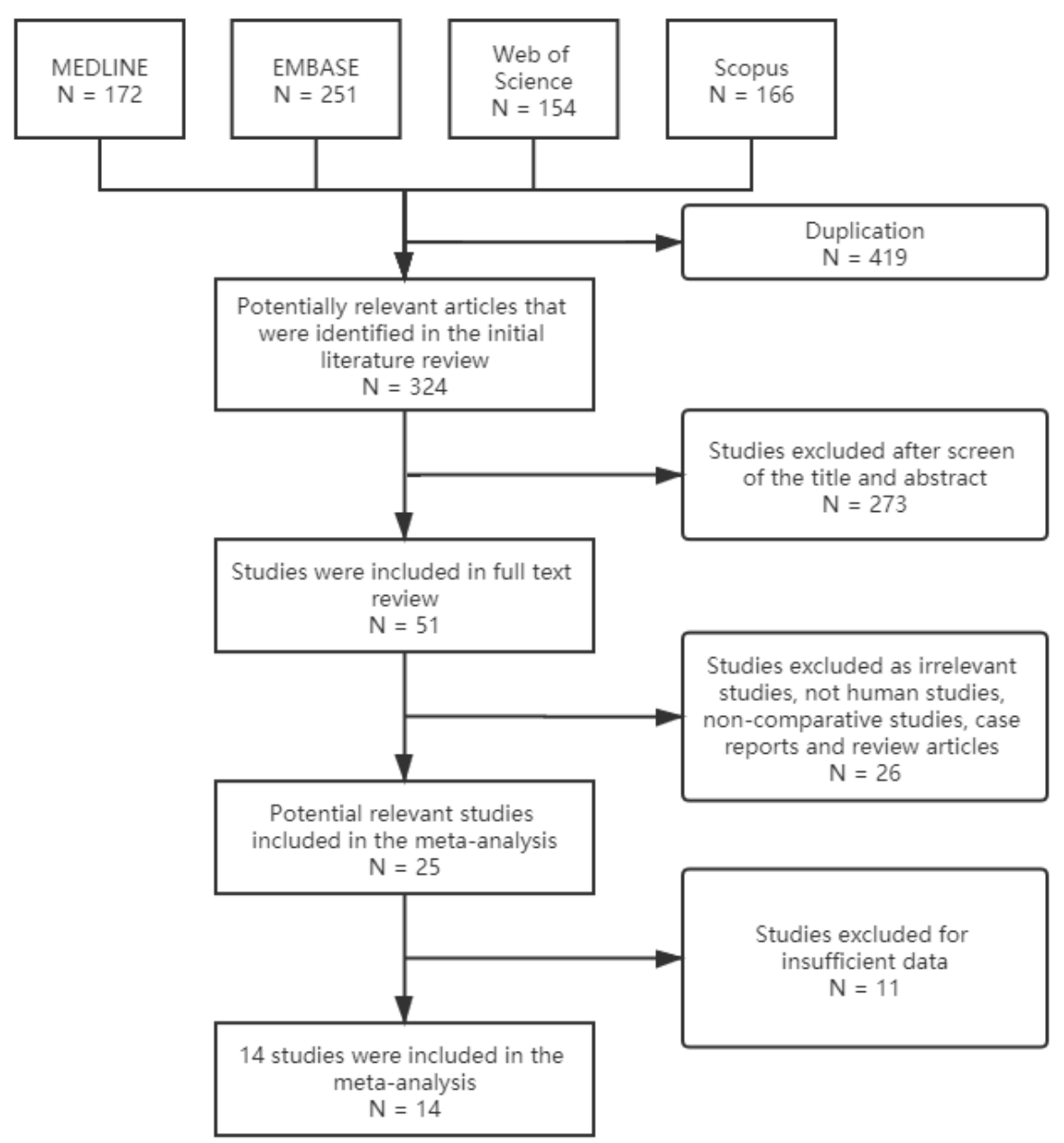

Figure 1

A flow diagram of the study selection.

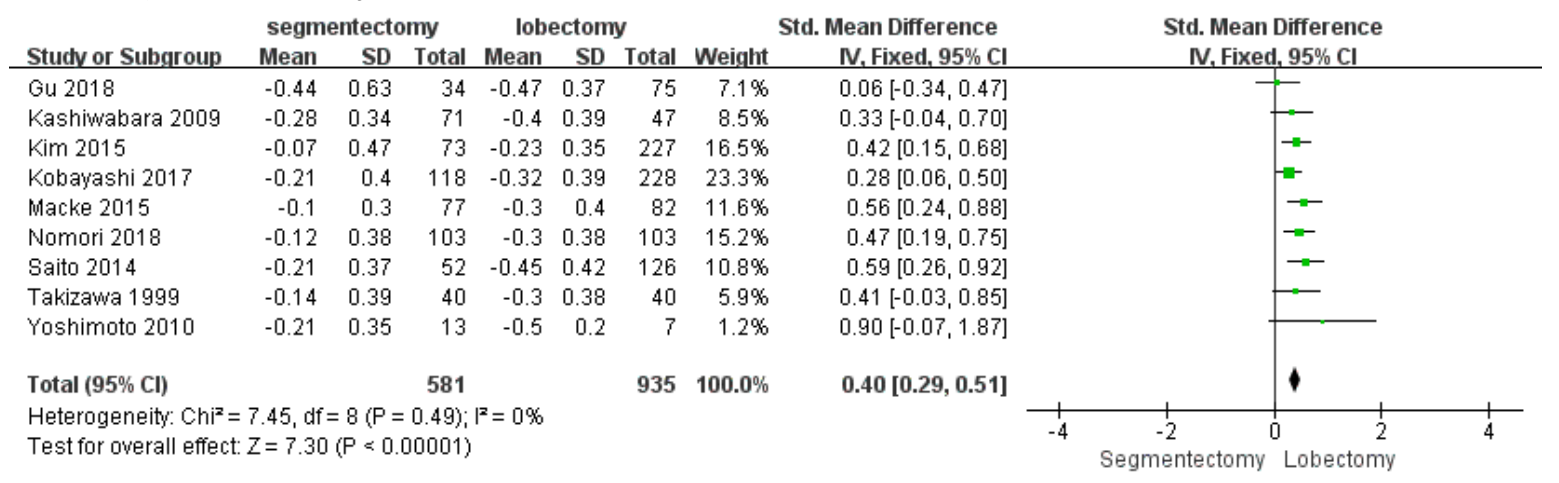

Figure 2

Weighted $\triangle \mathrm{FEV} 1$ between the segmentectomy group and the lobectomy group.

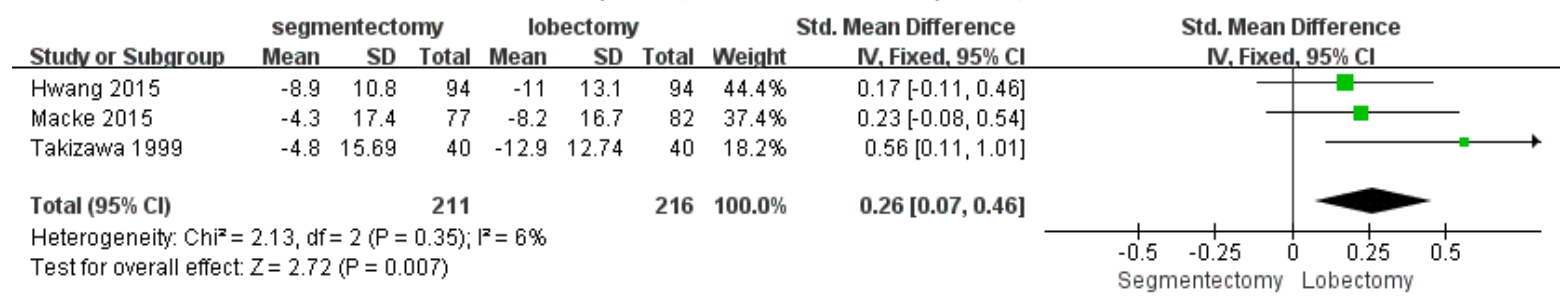


Weighted $\triangle \mathrm{FEV} 1 \%$ between the segmentectomy group and the lobectomy group in Stage IA patients.

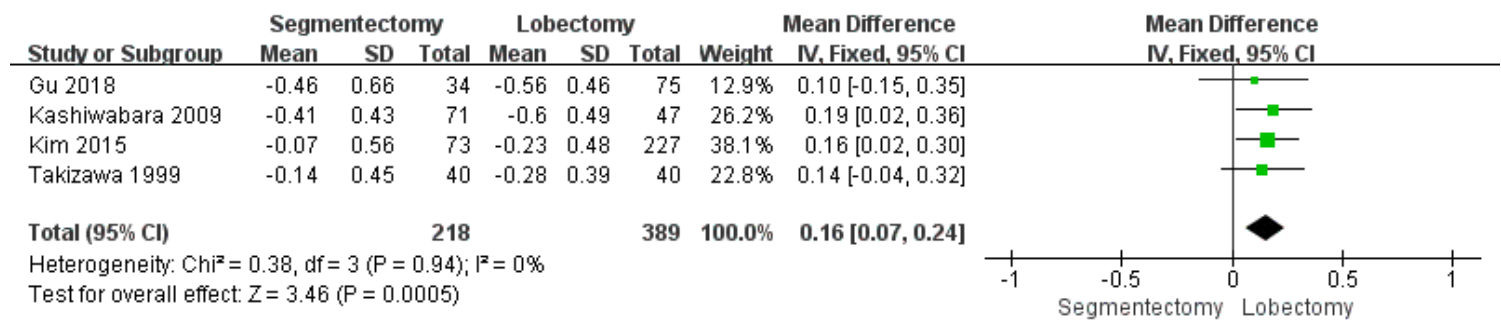

\section{Figure 4}

Weighted $\triangle \mathrm{FVC}$ between the segmentectomy group and the lobectomy group.

\begin{tabular}{|c|c|c|c|c|c|c|c|c|c|}
\hline \multirow[b]{2}{*}{ Studv or Subgroup } & \multicolumn{3}{|c|}{ Segmentectomy } & \multicolumn{3}{|c|}{ Lobectomy } & \multicolumn{2}{|c|}{ Mean Difference } & \multirow{2}{*}{$\begin{array}{l}\text { Mean Difference } \\
\text { IV, Fixed, } 95 \% \mathrm{CI}\end{array}$} \\
\hline & Mean & SD & Total & Mean & SD & Total & Weight & IV, Fixed, 95\% Cl & \\
\hline Kim 2015 & -1.54 & 8.47 & 73 & -6.29 & 10.74 & 227 & $52.5 \%$ & $4.75[2.36,7.14]$ & \\
\hline Takizawa 1999 & -6.1 & 12.01 & 40 & -9.6 & 10.02 & 40 & $12.8 \%$ & $3.50[-1.35,8.35]$ & \\
\hline Zhong 2020 & -10.5 & 9.24 & 68 & -13.7 & 8.7 & 76 & $34.7 \%$ & $3.20[0.26,6.14]$ & \\
\hline Total $(95 \% \mathrm{Cl})$ & & & 181 & & & 343 & $100.0 \%$ & $4.05[2.32,5.79]$ & \\
\hline $\begin{array}{l}\text { Heterogeneity: } \mathrm{Chi}^{2} \\
\text { Test for overall effec }\end{array}$ & $\begin{array}{l}0.70, \mathrm{df} \\
Z=4.58\end{array}$ & $\begin{array}{l}=2(P= \\
(P<0 .\end{array}$ & $\begin{array}{l}0.71) ; 1 \\
0001)\end{array}$ & ${ }^{2}=0 \%$ & & & & & $\begin{array}{ccc}-2 & 0 & 2 \\
\text { ntectomy } & \text { Lobecto }\end{array}$ \\
\hline
\end{tabular}

\section{Figure 5}

Weighted $\triangle \mathrm{FVC} \%$ between the segmentectomy group and the lobectomy group.

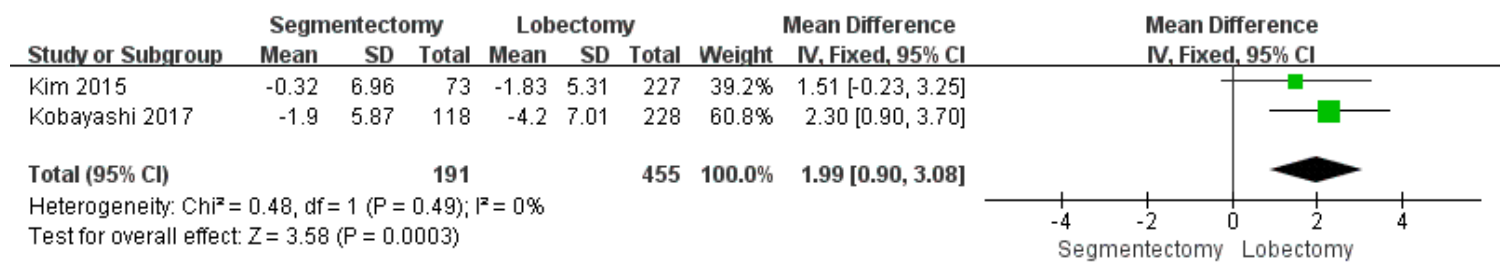

\section{Figure 6}

Weighted $\triangle \mathrm{FEV} 1 / \mathrm{FVC}$ between the segmentectomy group and the lobectomy group.

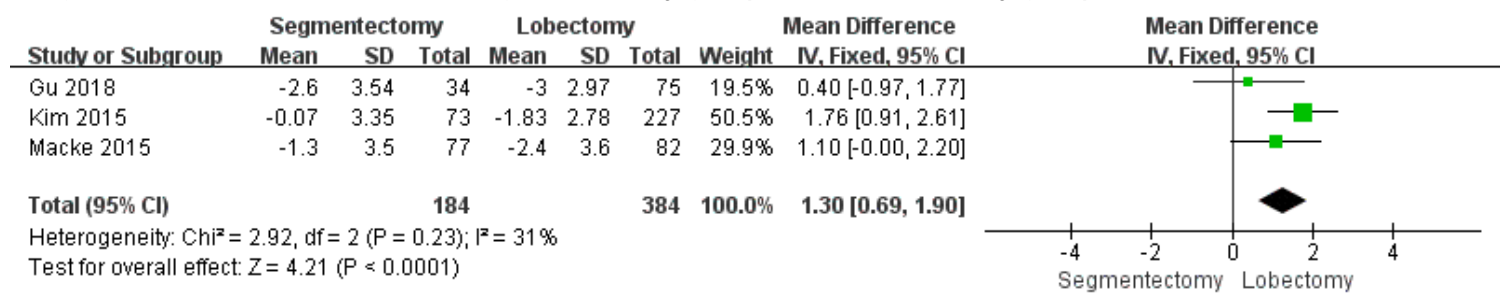

Figure 7

Weighted $\triangle \mathrm{DLCO}$ between the segmentectomy group and the lobectomy group.

\section{Supplementary Files}

This is a list of supplementary files associated with this preprint. Click to download.

- Figures1.png

- Figures2.png

- FigureS3.png

- Figures4.png

- FigureS5.png 